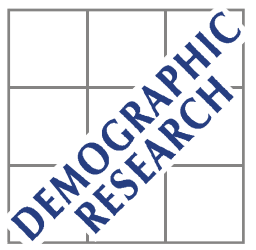

Demographic Research a free, expedited, online journal of peer-reviewed research and commentary in the population sciences published by the Max Planck Institute for Demographic Research Konrad-Zuse Str. 1, D-18057 Rostock · GERMANY www.demographic-research.org

DEMOGRAPHIC RESEARCH

SPECIAL COLLECTION 3, ARTICLE 2

PUBLISHED 17 APRIL 2004, PAGES 15-44

www.demographic-research.org/special/3/2/

DOI: 10.4054/DemRes.2004.S3.2

Research Article

\title{
Becoming an Adult in Europe: \\ A Macro(/Micro)-Demographic Perspective
}

Francesco C. Billari

This special collection is in honor of Jan M. Hoem on his $65^{\text {th }}$ birthday. The authors presented their papers at a working party at the Max Planck Institute for Demographic Research in Rostock, Germany in April 2004.

The collection is edited by Gunnar Andersson and Gerda Neyer.

(C) 2004 Max-Planck-Gesellschaft. 


\section{Table of Contents}

1 The importance of (micro- and) macro-level 16 extremes: oldest-old and lowest-low. What about latest-late?

2 European diversity in the transition to adulthood: 18

2.1 Macro-level explanations of international $\quad 20$ differences: institutional and conjunctural factors, long-term cultural differences and ideational change

2.2 Micro-macro interactions: from small at micro to 26 large at macro?

3 Macro-macro relationships: some interesting cross- $\quad 30$ country correlations with age at leaving home (are there two patterns?)

4 Discussion $\quad 33$

5 Acknowledgements $\quad 34$

$\begin{array}{ll}\text { Notes } & 35\end{array}$

$\begin{array}{ll}\text { References } & 37\end{array}$ 


\title{
Becoming an Adult in Europe: A Macro(/Micro)-Demographic Perspective
}

\author{
Francesco C. Billari ${ }^{1}$
}

\begin{abstract}
Extreme cases in demography are important challenges for researchers, and the still important heterogeneity of European societies is a blessing for scholars interested in studying the importance of cultural and institutional factors. In the transition to adulthood the "latest-late" pattern of Southern Europe cohabits with its opposite "earliest-early" pattern of the Nordic countries. In this paper, I discuss multifaceted approaches to the explanation of why becoming an "adult" in Europe appears so diverse. I use secondary data analyses and present cross-country correlations: welfare state and institutional arrangements, historical and deeply rooted cultural differences, as well as economic and policy factors, and ideational change. Moreover, micro-level determinants play different roles in different societies. Future research on the transition to adulthood in Europe needs to be multilevel, comparative and interdisciplinary, and to consider the potential implication of persistent differences in patterns.
\end{abstract}

Istituto di Metodi Quantitativi, Università Bocconi, Milano, Italy; and Innocenzo Gasparini Institute for Economic Research, Milano, Italy. E-mail: francesco.billari@uni-bocconi.it. 


\section{The importance of (micro- and) macro-level extremes: oldest-old and lowest-low. What about latest-late?}

Demographic research has always been profoundly influenced by population trends. These trends have affected both the object of the discipline ("What do demographers study?") and the methods and techniques used ("How do demographers study the issues they are interested in?"). Let us for instance look at recent decades. Research on longevity has been substantially influenced by the emergence of the oldest-olds. More recently, research on fertility has been influenced by the fact that some countries have reached what have been defined as lowest-low fertility levels. Changes in fertility and survival have been important seeds in the development of research directions at the new Max Planck Institute for Demographic Research (Wachter, 2003). Some researchers have even pointed out that the emergence of long lives, low fertility, and high immigration has contributed to the creation of a "new demography" (Vaupel, 2000; see also Kohler, 2000).

The extreme cases of demography are sometimes located at the macro, societal level (nations, regions), and sometimes at the individual or household level. Let us think, for instance, about oldest-old longevity (with extreme cases at the individual, micro-level, i.e. centenarians and super-centenarians), and lowest-low fertility (with extreme cases at the societal, macro-level, i.e. Italy, Spain and Central and Eastern European countries). Our main argument will be that attention on extreme cases can be rewardingly broadened to point at another type of macro-level: latest-late transition to adulthood and to contrast it with the opposite situation. "Latest-late" has been used by Billari et al. (2002) to describe the peculiar pattern of late home-leaving, union formation, and transition to parenthood of Italy and Spain. This pattern can only be partially compared with the general postponement in the transition to parenthood, typical of the "Second Demographic Transition" accompanying Western Europe over the last decades of the Twentieth century, as illustrated by Lesthaeghe and van de Kaa (Lesthaeghe and van de Kaa, 1986; van de Kaa, 1987). The postponement of first births has indeed taken place in all Western European countries and in most Central and Eastern European countries, although at different paces (Lesthaeghe, 2001). This general trend has also led to the idea that a distinct "postponement transition" is guiding recent transitions to parenthood (Kohler et al., 2002). However, the trend in postponement is not necessarily similar for all countries and for all events shaping the transition to adulthood, i.e. leaving home and union formation (Billari, 2004).

We can foresee that the "new demography" of Europe and of developed countries will take advantage of research carried out on oldest-old longevity, lowest-low fertility, and latest-late transition to adulthood. Extreme cases will thus shape the content of demographic research, by providing puzzles, in addition to the new developments in 
methodology. In this paper, we shall focus - adopting a demographic point of view - on household and family events taking place during what have been defined as the young adult years (i.e. more or less from age 18 to 34), years that are "demographically dense" (Rindfuss, 1991). This stage of the life course has been an important challenge for demographers in previous years, and has occupied an increasingly wide space in the agenda of scholars (Liefbroer, 1999). Our title "Becoming an Adult in Europe" is inspired by a similar title (and paper) by Hobcraft and Kiernan (1995), who discuss the standard "endpoint" of the transition to adulthood: "Becoming a Parent in Europe". We have also borrowed the idea from Hobcraft and Kiernan to base the general reflection on life-course transitions on empirical trends and innovative works from the literature pointing to multifaceted explanations, and the focus on Europe. As a matter of fact, Europe provides an extremely interesting setting to study the transition to adulthood. Cultural and institutional heterogeneity, economic differences and the interaction between them, have shaped an incredibly diverse way of "becoming an adult" in a demographic sense. Contemporary diversity in pathways to adulthood has become evident when the data from Fertility and Family Surveys have become available for a large set of European countries (Corijn and Klijzing, 2001). This diversity appears to be challenging also to scholars who have extensive experience in studying the transition to adulthood, and who realize that Europe provides an excellent field for investigation (Goldscheider, 2000). Fernandez Cordón (1997) has argued that in a time of overall social and economic convergence in European countries, it is hard to find social indicators with such striking differences among EU countries as those related to the transition to adulthood. The differences between societies are striking, but intra-society heterogeneity is massive as well. In fact, one can predict that individualization and path dependence may also produce a macro-level convergence to micro-level diversity (Billari and Wilson, 2001). Here, reporting analyses that are themselves heterogeneous, we shall reflect upon the heterogeneity at the macro-level by looking at the main explanatory ideas for societal differences in the transition to adulthood, and upon the micro-macro link (how some micro-level factors do interact with macro-level circumstances to shape the transition to adulthood) (Note 1).

The paper is structured as follows. In Section 2, after a short recall of the situation, we review the explanatory directions for diversity in European transitions to adulthood. We focus on macro-level differentials and on the interaction between such differential and micro-level determinants of life-course transitions. Pure macro relationships, with some speculations on the existence of two stable patterns, are illustrated and discussed in Section 3. The final section contains some ideas on future directions in research. 


\section{European diversity in the transition to adulthood: explanatory directions and their interactions}

European diversity, both in states and trajectories of patterns in transition to adulthood, is a clear challenge for researchers interested in the topic, as it has been since early pioneering studies (Kiernan, 1986). It is also a challenge for those who want to investigate whether a modernization process is guiding demographic behavior in Europe, and whether there will be a convergence in demographic behavior (Goldscheider, 2000; Coleman, 2002). This appears clearly from data from the Fertility and Family Surveys held (mostly) during the 1990s. We chose a simple indicator: the share of individuals having left home, formed a union, and having become parents by age 25 (for women, see Table 1). Similar results are obtained by looking at different indicators. In the literature we can also find analyses of the sequencing of events using FFS data, showing similar degrees of heterogeneity between nations (Billari et al., 2001; Corijn and Klijzing, 2001; Billari and Wilson, 2001).

To start our discussion on explanatory directions, we can allude to two opposite patterns in age at home-leaving: 1) the "latest-late" pattern in Southern Europe, with late transitions that are highly de-standardized by age, but very standardized vis-à-vis the relationship to union formation; 2) the "earliest-early" pattern of transition of Nordic countries (the term is willingly exaggerated) where the detachment from parental home takes place around age 19/20, with a high age standardization and a more diverse connection with union formation. Other European societies may be considered to be in between such extreme cases. Why is there such diversity? And why is such diversity narrowing, showing convergence for some behavior, while it is even increasing, with signs of divergence, for other types of behavior? An answer to such questions is more the task of an entire research program than the capacity of a paper. Here we shall sketch some of the explanatory directions that have been taken, distinguishing macro-level factors and trends, and the interaction between macro- and micro-level factors. We shall put a particular emphasis on the latter point and in particular on 1) how micro-level determinants can have different weight in different macro-level situations and 2) how social interactions may shape the transition to adulthood (especially in terms of postponement of events). 
Demographic Research - Special Collection 3: Article 2

-- Contemporary Research on European Fertility: Perspectives and Developments --

Table 1: $\quad$ Women having experienced demographic events by the $25^{\text {th }}$ birthday, two cohorts at 10-year distance: estimates from the Fertility and Family Surveys.

\begin{tabular}{|c|c|c|c|c|c|c|c|}
\hline \multirow[b]{2}{*}{ Country } & \multirow[b]{2}{*}{ Cohorts } & \multicolumn{3}{|c|}{ Cohort 1} & \multicolumn{3}{|c|}{ Cohort 2} \\
\hline & & $\begin{array}{c}\text { Have left the } \\
\text { parental } \\
\text { home }\end{array}$ & $\begin{array}{c}\text { Have entered a } \\
\text { co-resident } \\
\text { union } \\
\end{array}$ & $\begin{array}{c}\text { Have } \\
\text { become } \\
\text { mothers }\end{array}$ & $\begin{array}{c}\text { Have left the } \\
\text { parental } \\
\text { home }\end{array}$ & $\begin{array}{c}\text { Have entered a } \\
\text { co-resident } \\
\text { union } \\
\end{array}$ & $\begin{array}{l}\text { Have } \\
\text { become } \\
\text { mothers }\end{array}$ \\
\hline \multirow[t]{2}{*}{ Austria } & (1) $1956-61$ & 86.1 & 74.8 & 52.5 & 83.0 & 70.2 & 43.4 \\
\hline & (2) 1966-71 & & & & & & \\
\hline \multirow{2}{*}{$\begin{array}{l}\text { Belgium (Flemish } \\
\text { speaking) }\end{array}$} & (1) $1951-56$ & 89.3 & 86.1 & 47.1 & 82.3 & 75.7 & 26.3 \\
\hline & (2) $1961-66$ & & & & & & \\
\hline \multirow[t]{2}{*}{ Bulgaria } & (1) $1958-62$ & n.a. & 75.6 & 69.6 & n.a. & 71.9 & 69.4 \\
\hline & (2) $1968-72$ & & & & & & \\
\hline \multirow[t]{2}{*}{ Czech Republic } & (1) $1958-62$ & 84.2 & 68.8 & 76.6 & 86.9 & 78.0 & 72.4 \\
\hline & (2) $1968-72$ & & & & & & \\
\hline \multirow[t]{2}{*}{ Estonia (native born) } & (1) $1954-58$ & 79.1 & 73.2 & 68.2 & 76.0 & 79.0 & 69.1 \\
\hline & (2) $1964-68$ & & & & & & \\
\hline \multirow[t]{2}{*}{ Finland } & (1) $1950-54$ & 90.2 & 75.7 & 49.1 & 91.0 & 77.8 & 36.1 \\
\hline & (2) $1960-64$ & & & & & & \\
\hline \multirow[t]{2}{*}{ France } & (1) $1954-58$ & 88.8 & 81.7 & 57.5 & 86.6 & 76.1 & 36.4 \\
\hline & (2) $1964-68$ & & & & & & \\
\hline \multirow[t]{2}{*}{ Greece } & (1) $1960-64$ & 83.3 & 75.5 & 54.5 & 72.8 & 54.9 & 34.8 \\
\hline & (2) $1970-74$ & & & & & & \\
\hline \multirow[t]{2}{*}{ Hungary } & (1) $1953-57$ & 80.4 & 85.9 & 71.8 & 80.6 & 83.8 & 66.0 \\
\hline & (2) $1963-67$ & & & & & & \\
\hline \multirow[t]{2}{*}{ Italy } & (1) $1956-60$ & 67.7 & 61.2 & 44.3 & 64.7 & 40.7 & 23.5 \\
\hline & (2) $1966-70$ & & & & & & \\
\hline \multirow[t]{2}{*}{ Latvia } & (1) $1955-60$ & 71.3 & 81.4 & 70.6 & 58.8 & 80.8 & 68.6 \\
\hline & (2) $1965-70$ & & & & & & \\
\hline \multirow[t]{2}{*}{ Lithuania } & (1) $1955-60$ & 74.4 & 77.5 & 62.4 & 63.7 & 76.9 & 70.4 \\
\hline & (2) $1965-70$ & & & & & & \\
\hline \multirow[t]{2}{*}{ Netherlands } & (1) $1953-58$ & 92.6 & 81.1 & 32.3 & 88.9 & 71.3 & 19.8 \\
\hline & (2) $1963-68$ & & & & & & \\
\hline \multirow[t]{2}{*}{ Norway } & (1) 1950 & 88.7 & 78.0 & 58.1 & 90.7 & 78.5 & 44.2 \\
\hline & (2) 1960 & & & & & & \\
\hline \multirow[t]{2}{*}{ Poland } & (1) $1952-56$ & 66.8 & 73.0 & 64.2 & 62.3 & 74.0 & 65.4 \\
\hline & (2) $1962-66$ & & & & & & \\
\hline \multirow[t]{2}{*}{ Portugal } & (1) $1957-62$ & 72.1 & 70.6 & 61.8 & 60.7 & 58.5 & 43.5 \\
\hline & (2) $1967-72$ & & & & & & \\
\hline \multirow[t]{2}{*}{ Slovenia } & (1) $1956-60$ & 82.0 & 84.9 & 80.5 & 77.4 & 83.8 & 69.7 \\
\hline & (2) $1966-70$ & & & & & & \\
\hline \multirow[t]{2}{*}{ Spain } & (1) $1955-60$ & 73.3 & 71.2 & 50.0 & 56.6 & 53.3 & 33.2 \\
\hline & (2) $1966-70$ & & & & & & \\
\hline \multirow[t]{2}{*}{ Sweden } & (1) 1954 & 95.0 & 82.2 & 47.6 & 96.7 & 79.8 & 36.9 \\
\hline & (2) 1964 & & & & & & \\
\hline \multirow[t]{2}{*}{ Switzerland } & (1) $1950-54$ & 95.0 & 68.1 & 34.7 & 93.9 & 66.2 & 27.1 \\
\hline & (2) $1960-64$ & & & & & & \\
\hline
\end{tabular}

Source: UN/ECE FFS Standard Country Tables: http://www.unece.org/ead/pau/ffs/ffs_standtabframe.htm. 


\subsection{Macro-level explanations of international differences: institutional and conjunctural factors, long-term cultural differences and ideational change}

Macro-level factors affecting the transition to adulthood can be, in a simplified view, categorized on a $2 \times 2$ table. On one dimension of the table we can put the traditional "culture vs. economy" dichotomy. In this paper we take a broad view of economy as "political economy" or "political economics" (Persson and Tabellini, 2000): our notion of economy includes economic trends, institutional settings and the welfare state (i.e. the broad interactions between the economic and political setting). On the other dimension of the table, we can put the historical stability of macro-level factors (slowly changing vs. quickly changing). The transition to adulthood in European nations is shaped, on the one hand, by slowly changing institutional factors (i.e. the welfare state), as well as by specific socio-economic policies (i.e. labor market or housing policies, that is, factors that change more quickly than institutions) (Note 2). In fact, seminal papers have indicated the transition to adulthood as an illustrative case of a set of problems concerning the way institutional constraints affect the construction of the life course (Modell et al., 1976). On the other hand, the way one becomes an adult in a demographic sense is shaped by long-term cultural differences that have deep historical roots (i.e. normative expectations and ideals on intergenerational relationships and family ties), as well as by ideational factors whose dynamics is faster than long-term cultural differences (i.e. value orientations). All such factors are important in shaping actual differences between countries, although each of the four types of explanatory factors actually refers to a different scholar tradition.

As far as institutional factors are concerned, they are of primary interest to scholars interested in studying the welfare state, and they are connected to long-term differences between countries in the transition to adulthood that are resisting forces driving convergence. In particular, the idea that different welfare regimes exist, each with specific life course consequences, is at the heart of the work of Esping-Andersen (1999) and Mayer (2001). The main issue in the literature concerns the number of welfare regimes we should use to describe current institutional settings in Europe. So far, a principal focus has been on Western Europe. A three-world categorization was first proposed by Esping-Andersen, who also leaves the door open for a four-world categorization (Note 3) - including 1) Social democratic (Nordic) welfare regimes oriented to individuals; 2) Liberal market welfare regimes (again oriented to individuals); 3) Conservative continental welfare regimes oriented to the family, and 4) Southern European or Familistic (Note 4) welfare regimes (Note 5). Each of the regimes shapes, in a completely different way, the whole "package" of behaviors in the transition to adulthood (as an example we report the predictions of Mayer in Table 2). In fact, the emergence of modern welfare states is one of the main factors that have 
contributed to the "institutionalization" of the life course, and such institutionalization has been mostly concerned with the transition to adulthood (Mayer and Müller, 1986). This influence is also going to continue: Blossfeld (2000), for instance, has argued that country-specific institutions will channel the way through which the globalization of economic life will affect life courses of individuals in developed countries, thus preventing life courses from becoming more similar.

As a caveat, and to get back to the economy (or institution) vs. culture debate, prominent scholars in the literature on welfare regimes note that such regimes cannot be taken as purely exogenous in the long-run perspective (Mayer, 2001). For instance, whether a society encourages young adults to attend higher education at universities with on-campus accommodation, as opposed to having local universities where young adults and their parents can co-reside for a longer period, depends on the prevailing views of inter-generational relationships. The causal link would then be from the cultural framework to the making of institutional settings, which would mean that in a longer causation chain, long-term cultural differences explain a substantial part of the differences in family (Pfau-Effinger, 1999) and social policies.

Table 2: $\quad$ Prediction of life course outcomes in four types of political economies according to Mayer.

\begin{tabular}{lllll}
\hline & Liberal & Conservative & Social Democratic & Familistic \\
\hline $\begin{array}{l}\text { Age at leaving home } \\
\text { Age at leaving }\end{array}$ & Early, high variance & Medium, high variance & Early, low variance & Late, high variance \\
school/training & Medium homogeneous & High stratified & Medium & Low stratified \\
Labor market entry & Early, stop-gap, low skill & Late, integrated, high skill & Early, integrated & Late, marginal \\
\hline
\end{tabular}

Source: adapted from Mayer (2001).

Social and economic policies that are in place during a specific time period also significantly shape the transition to adulthood. We refer, for instance, to specific policies (i.e. fiscal policies, family policies, housing policies, labor-market policies) that may change faster than the institutional setting. This is also true of specific economic trends that are not explicitly under the control of national policy-makers (see i.e. Andersson, 2000; Hoem, 2000 on the transition to parenthood and fertility). Economic trends and socio-economic policies are so clearly interrelated that it is often not possible to identify their separate effects on demographic behavior (see i.e. Hoem and Hoem, 1997). The adoption of new policies, i.e. on housing subsidies or on limits to downpayment in mortgages, are clearly important determinants of how young adults shape 
their pathways to adulthood, and the same is true for family policies, such as maternity policies, parental-leave policies, childcare services, and child benefits (Neyer, 2003). It is difficult to disentangle whether such policies belong to the welfare state per se (and thus are stable in a mid-term historical perspective), or whether they belong to political choices that are continuously subject to revision. In any case, changes in such policies modify the opportunities that young adults face during their early adult years, and they can be read in the classic demographic terms of "period effects". The spread of uncertainty in young adulthood, as in the case of increasingly difficult access to the labor market, as well as other factors, for instance increases in the return to education, may also explain period trends and differences (Bernardi, 2000). In fact, the latter type of factors has been used by Kohler et al. (2002) to argue that postponement of the transition to parenthood (but similarly, of other demographic events during early adulthood) may arise as a rational response to socio-economic incentives. Socioeconomic conjunctural factors may explain sudden changes in patterns in a country, and they may constitute macro-events that trigger changes having long-term consequences. Such conjunctural factors are, however, unlikely to explain long-term stable differences between societies. But we shall return to the issue in Section 2.2.

Concerning long-term cultural differences that form the basis of present differences in behavior, we may distinguish the literature along east-west and northsouth divides. Of course, these divisions are necessarily simplistic (similar to divisions according to welfare regimes). Hajnal (1965) (Note 6) traces an east-west divide in historical family systems in Europe: the Hajnal line runs along an imaginary line connecting Trieste and St. Petersburg. To the west of the line the family formation pattern leans towards a neo-local nuclear family, with relatively late marriage and a significant proportion of people who never married. Of those not marrying, most of the people leave the parental home anyway. To the east of the line, marriage is supposed to be early and universal, and the family is often extended. However, this last feature has an ambivalent impact. Early and generalized leaving home occurs for those who marry early without staying with their parents. Those who marry and stay with their parents may continue living with their parents for a long time, and in some cases they may also opt for co-residence with their parents as a permanent solution. A great heterogeneity has been shown by studies focusing to the west of the Trieste-St. Petersburg line. Preindustrial patterns within the West show that early home leaving prior to marriage was common in many areas (Laslett, 1983; Wall, 1989; Mitterauer, 1992). In the central and north-western parts of the continent, a significant percentage of young people spent a more or less prolonged period of time outside their parents' household, normally involved as rural servants or as urban workers. As a consequence, young people often left the parental household long before marriage. The same was not true in other areas of South-western Europe, where time spent as servants was normally short-lived, and 
only involved a small percentage of the population. Nevertheless, the existing picture of historical co-residential patterns is far from complete, and it shows considerable geographical and historical variance. Specific demographic, economic, and cultural factors determined family and household systems (just as they do today), including considerable regional variations on attributes such as the welfare capability of the family, the functioning of the household as a working unit, the role and status of women, marriage patterns, and co-residence of kin, among others (Wall, 1995). The presence of long-term cultural continuities, in particular concerning the strength of inter-generational ties between societies, has been emphasized by scholars looking at differences between North-western and South-western Europe (Reher, 1998; Micheli, 2000; Dalla Zuanna, 2001). Reher (1998), for instance, systematically and comprehensively compares historical and current family patterns in Europe, west of the Trieste-St. Petersburg line. He emphasizes the Southern European pattern of household formation, relating a cleavage between two patterns to the times of the late Roman Empire and the early Middle Ages. According to Reher, in Southern Europe, the influence of Muslims raised the importance of kinship and vertical relationships between generations, so that the prolonged stay of children in their parents' home and the caring work of children towards their parents are two faces of the same coin, a "strong" family. Some authors emphasize historical continuity up to the extreme, substantially denying that there is anything new in the transition to adulthood of Italians, and that "latest-late" transition have traditionally been there (Barbagli et al., 2003). In the North, Germanic tradition and the Reformation contributed to the development of a "weak" family. Such differences have contributed to shape institutional settings at the societal level, with, for instance, welfare states implicitly or explicitly favoring various types of living arrangements (Holdsworth, 2000). Besides differences in the actual timing of life course transitions, it is interesting to notice that the share of young adults who declare to be dependent on parents and/or family members for their income (now the majority in the EU 15) is by far larger in "strong ties" and familistic societies with respect to "weak ties" social-democratic societies (Table 3). This dependence also translates in larger inter vivos transfers from children to parents during key events in the transition to adulthood, and with a larger geographical proximity after residential independence (Glaser and Tomassini, 2000; Tomassini et al., 2003). 
Demographic Research - Special Collection 3: Article 2

-- Contemporary Research on European Fertility: Perspectives and Developments --

Table 3: $\quad$ Share of young adults (age 15-24) who declare to be dependent on their parents or family members. European Union (15 states).

\begin{tabular}{lcc}
\hline & \% dependent on parents/family \\
& 1997 & 2001 \\
\hline Austria & 41 & 43 \\
Belgium & 48 & 58 \\
Denmark & 19 & 19 \\
Finland & 41 & 40 \\
France & 48 & 61 \\
Germany & 38 & 46 \\
Germany (East) & 35 & 46 \\
Germany (West) & 38 & 46 \\
Greece & 51 & 71 \\
Ireland & 38 & 32 \\
Italy & 68 & 74 \\
Luxembourg & 58 & 66 \\
Netherlands & 33 & 43 \\
Portugal & 51 & 54 \\
Spain & 62 & 67 \\
Sweden & 34 & 39 \\
United Kingdom & 17 & 21 \\
EU 15 & 45 & 54 \\
Coefficient of variation between & & 3.22 \\
countries & 3.24 & \\
\hline
\end{tabular}

Source: Eurobarometer (INRA, 2001). The coefficient of variation is computed using the data for Germany only (not distinguishing East and West Germany).

Interpretations based on ideational change, clearly connected to modernization theories, have almost become a paradigm for the interpretation of demographic change in Western societies, with the key idea of a Second Demographic Transition starting in the 1960s (Lesthaeghe and van de Kaa, 1986; van de Kaa, 1987). The main factors advocated by the proponents of ideational change as the main motor are the accentuation of individual autonomy, the rejection of institutional control and autonomy, and the rise of values associated to "higher order needs" (see i.e. Surkyn and Lesthaeghe, 2004). The emergence of "new" behaviors (like unmarried cohabitation and single living) during early adult years, has been taken as one of the signs of the process of individualization of life courses which is used to depict the evolution of 
Western European and North American societies towards a "new modernity" (Buchmann, 1989; Beck, 1992; Giddens, 1990). Individualization implies that the normative regulation of life courses becomes more lenient than in the past (somehow differently from the idea that life courses are institutionalized by the welfare state) (Note 7). We can locate the ideational change point of view within a "developmental" idea of societies that is common among demographers analyzing long-term trends: societies are assumed to develop through stages over a sequence leading to a certain direction. This idea, intertwined with the notion of "transition", has had an impressive impact on demographic research (Thornton, 2001). Of course, cross-country analyses in a specific period do not necessarily provide perfect tests for the transition to new situations, because if transitions follow specific sequences, different societies can be found in different stages of such a sequence (van de Kaa, 1997) (Note 8). During a transition, there may also be rise in the difference between societies. A simple instance of continuity and change in ideas is reported in Table 4, where we can see data from the Eurobarometer on young people aged 15-24 from the EU 15 in 1997 and 2001. Taking indicators of secularization and tolerance, for instance those related to the rights of homosexuals to get married and/or to adopt children, we can see that young Europeans are still fairly heterogeneous, and that the heterogeneity between countries has even risen when looking at a simple indicator such as the coefficient of variation between countries.

To sum up, no single approach is in principle satisfactory per se in explaining differences in the transition to adulthood in Europe, let alone extreme cases such as the "latest-late" pattern of Southern Europeans. It is plausible to think that all factors play a role and intersect in creating an extreme situation. The Southern European familistic welfare regime, as predicted for instance by Mayer, pushes the postponement of young adult transition further to later ages. The lack of social policies (i.e. unemployment protection) and the weakness of family policies constitute a further element, together with rising uncertainty in a two-tier labor market. In addition, strong links between parents and children and long co-residence are not at all new under the Southern sun, as researchers who are scrutinizing history emphasize. Furthermore, ideational changes that have taken place in most other parts of Europe will still take some time to evolve in the Southern region. The challenge for research, and for policymakers interested in helping young people make their choices, is to evaluate the relative weight of the different factors in shaping the extreme case. Needless to say, different combinations of the factors may explain the other side of the extreme (i.e. the Nordic pattern of transition to adulthood). We shall go back to this idea in Section 3. Prior to that, we shall discuss how the impact of micro-level factors is channeled through the macrolevel contextual determinants that we have discussed so far. 
Demographic Research - Special Collection 3: Article 2

-- Contemporary Research on European Fertility: Perspectives and Developments --

Table 4: $\quad$ Share of young adults (age 15-24) in favor of the rights of homosexuals 1) to get married; 2) to adopt children: 1997 and 2001. European Union (15 states).

\begin{tabular}{lcccr}
\hline & Get married & \multicolumn{3}{c}{ Adopt children } \\
\cline { 2 - 5 } & 1997 & 2001 & 1997 & 2001 \\
\hline Austria & 41 & 66 & 33 & 48 \\
Belgium & 49 & 63 & 30 & 40 \\
Denmark & 71 & 82 & 38 & 54 \\
Finland & 59 & 65 & 24 & 30 \\
France & 56 & 66 & 43 & 43 \\
Germany & 43 & 57 & 35 & 46 \\
Germany (East) & 36 & 53 & 34 & 47 \\
Germany (West) & 45 & 59 & 36 & 45 \\
Greece & 47 & 38 & 29 & 24 \\
Ireland & 36 & 44 & 27 & 27 \\
Italy & 40 & 39 & 21 & 20 \\
Luxembourg & 59 & 59 & 38 & 45 \\
Netherlands & 80 & 85 & 64 & 62 \\
Portugal & 50 & 62 & 32 & 29 \\
Spain & 76 & 74 & 53 & 54 \\
Sweden & 60 & 76 & 20 & 41 \\
United Kingdom & 43 & 50 & 30 & 43 \\
EU 15 & 52 & 59 & 36 & 41 \\
Coefficient of variation between & 3.98 & 4.23 & 3.16 & 3.50 \\
countries & & & &
\end{tabular}

Source: Eurobarometer (INRA, 2001). The coefficient of variation is computed using the data for Germany only (not distinguishing East and West Germany).

\subsection{Micro-macro interactions: from small at micro to large at macro?}

Differences among countries in behavior can also be due to differences in the population composition according to micro-level determinants. At one extreme, differences can be due to pure compositional effects. For instance, lower income for individuals means more limited possibilities to access housing at a given equal market price, and obviously a change in per-capita income at the national level implies that there will be more individuals with limited possibilities to access housing, market prices 
being equal. This may partially account for some differences, although the observed differences between Central/Eastern and Western Europe go in the opposite direction, as we could expect from this simple reasoning. Another possible source of compositional effects is education. For instance, individuals wishing to pursue higher education may be more prone to leave their parental home to move closer to universities, and the educational composition of a population may explain part of the differences in age at leaving home. But as we have noticed, at least among Western European countries, the amount of economic convergence is by far larger than the amount of convergence in pathways to adulthood.

Micro-macro interactions are more interesting for the purpose of this paper, both from the theoretical side and for the possibility of explaining national differences. Some factors at the macro-level are channeling the impact of micro-level characteristics on the transition to adulthood. In particular, we shall discuss two types of such interactions: 1) interactions between individual-level factors and the political-economic context; 2) social interactions that may shape the transition to adulthood, and that imply persisting national differences even when the underlying factors are no longer active. These types of interactions can fuel macro-level factors and contribute to perpetuating differentials, both between and within societies.

Among scholars interested in the impact of welfare regimes during the life course, there has been a long-lasting interest in comparing the impact of micro-level factors among different societies. An example of the interaction between individual-level factors and institutional context can be found for instance in the findings of Aassve et al. (2002). They argue that income differentials can partially explain the postponement of leaving home in several European societies, but what is most important is that the effect of income is different according to the welfare regime. Table 5 shows such impact. Earning an own income is more important for young adults living in Southern Europe and in liberal market welfare regimes (i.e. the U.K) than for those living in continental and social democratic welfare regimes. This implies that 1) individual-level differences in income are more important in accounting for differences in age at leaving home in countries where leaving home happens at the latest ages (consistently with predictions from Mayer, 2001 for example); 2) potential policies targeted at increasing the income of young adults may anticipate independent living more in countries where such independent living is postponed; 3 ) small differences in average income (i.e. percapita income in Southern Europe being slightly lower than the one in Northern Europe) may become amplified by the institutional arrangement, and thus account for national differences because of this interaction.

Another example of interaction is between individual-level factors and timevarying policies. Not only can policies affect the transition to adulthood, but socioeconomic or family policies may also affect different social strata in a different way. 
Aassve et al. (2003) analyze the impact of the transition from a general to a meanstested type of family allowance in Hungary during the mid-1990s. The impact of the policy change has been to broaden the age gap in the transition to motherhood between high and low social strata (represented by educational levels). As soon as the family allowance became universal again, the differences returned to the initial level. The interaction between micro-level and macro-level is also present in the interrelationships between events in the transition to adulthood: Baizán et al. (2002), for instance, have shown that out-of-union conceptions lead more often to marriage than to cohabitation in West Germany, with respect to Sweden. This can be explained by the presence of differences in both the fiscal treatment and the acceptability of pre-marital births in the two societies.

Table 5: $\quad$ Effects on the probability of leaving home, of being employed and having income in the upper quartile (inverse Mill's ratio). Estimates from the European Community Household Panel.

\begin{tabular}{lcc}
\hline & Males & Females \\
\cline { 2 - 3 } Denmark & 0.311 & 0.982 \\
France & 0.508 & 0.323 \\
Germany & -0.003 & 0.810 \\
Greece & 0.665 & 0.693 \\
Italy & 0.631 & 0.635 \\
Netherlands & 0.074 & -0.663 \\
Portugal & 1.199 & 0.965 \\
Spain & 1.239 & 0.926 \\
United Kingdom & 0.628 & 0.568 \\
\hline
\end{tabular}

Source: Aassve et al. (2002).

The lesson we can learn from micro-macro interactions on the determinants of the transition to adulthood is that there is nothing like the true effect of a variable when studying the life courses of Europeans. Europe is heterogeneous and ever changing. The institutional and cultural variables we have discussed in Section 2.1 are always - with variable extent - channeling the impact of micro-level factors, although one can devise groups of societies where similar outcomes may be predicted. The combination of measures of factors at both macro- and micro-level in the explanation of micro-level transitions to adulthood is certainly a promising avenue that will have to be followed in the years to come. 
As far as social interactions are concerned, they have been of primary interest in the recent demographic literature on fertility decline (i.e. Bongaarts and Watkins, 1996; Montgomery and Casterline, 1996; Kohler, 2001), and they have also been used as a possible explanation of lowest-low fertility (Kohler et al., 2002). Social interaction effects refer mainly to "social influence" and "social learning". Their peculiarities are such, as they may entail 1) social multiplier effects (similar to the ones we have noticed on the interaction between income and institutional setting), with overall behavioral impact that is larger than what has been initially triggered; 2) multiple equilibria, with more than one stable regime (i.e. early home-leaving such as in Nordic countries, and late home-leaving such as in Southern Europe); 3) status-quo enforcement and path dependence, where the present situations maintain long-term impact. As an example, the decision to stay in the parental home versus leaving is likely to be affected by social learning: young adults may use their friends as a point of comparison in their decision making about leaving home. In this case, a widespread postponement of home-leaving (i.e. like in Southern Europe) leaves fewer opportunities for social learning, and the postponement may become even more pronounced. The same impact is plausible for union formation, and for first births (Kohler et al., 2002). Other factors like social norms or feedback from the marriage market are included in the impact of social interaction. Of great importance for our argumentation here are the consequences for national-level differences in the transition to adulthood. We name two such consequences. First, the presence of multiple equilibria and path dependence imply a much stronger stability of long-term differences (i.e. based on long-term family models or on institutional settings), independently of the convergence in terms of other factors. Second, social interaction effects typically give rise to transitions that continue independently of the factors that originated from such transitions. The idea of postponement transition has been used by Kohler et al. (2002) to describe the postponement of first births, but it can be translated to other events during early adulthood, such as leaving home and first union. As we have seen from data on leaving home in Table 1, however, the postponement of home-leaving is not visible i.e. in Nordic countries, and this is particularly plausible as the present situation may be a stable equilibrium. In general, the postponement transition is visible for first births and marriage, while it is not widespread for first unions in general, and leaving home. We shall use the idea of multiple equilibria a bit later on to speculate on the presence of two extreme - and relatively stable - patterns of transition to adulthood in Europe. 
Demographic Research - Special Collection 3: Article 2

-- Contemporary Research on European Fertility: Perspectives and Developments --

\section{Macro-macro relationships: some interesting cross-country correlations with age at leaving home (are there two patterns?)}

We have referred to the timing and context of leaving the parental home as the event in the transition to adulthood, where both 1) international differences in Europe are importantly marked; and 2) there is no clear common trend, and on the contrary, there seem to be divergent trends with countries at one extreme ("latest-late") clearly postponing, and countries at the other extreme ("earliest-early"), stable in their early transition. We have also argued that a complex web of macro-level explanatory factors is necessary to get to the extreme case, and we have also argued that the macro-level factors may interact with micro-level determinants. In the fertility literature, there has been a recent upsurge of interest in the analysis of cross-sectional correlations as a tool to gain additional knowledge of the determinants of international differences. In particular, there is a line in the literature discussing the reasons of the changing crosscountry correlation between female labor force participation and fertility in the last part of the Twentieth century (see i.e. Ahn and Mira, 2002; Engelhardt and Prskawetz, 2004; Kögel, 2004). This approach has been generalized, and one can see that several crosscountry relationships between fertility and fertility-related behaviors have changed from the 1970s to the 1990s (Billari and Kohler, 2004). Here we follow this purely macro cross-national approach, and perform an exploratory analysis based on cross-country correlation coefficients to relate the timing of leaving home with a series of socioeconomic indicators on 1) the social and economic condition of youth and 2) the relationships between generations. Of course, cross-country correlations cannot be considered an indication of cause-effect relationship. We use them to discuss the macro-level ideas outlined above, with some provoking speculations, and to discuss the potential stability of the opposite situations "latest-late" and "earliest-early".

Table 6 reports the matrix of correlation coefficients between the median ages at leaving home derived from the FFS (Note 9) and other indicators, stemming mostly from OECD source. We focus on the first column, where we see the correlation of the various indicators with the timing of leaving home. As far as intergenerational relationships are concerned, we see that the median age at leaving home is positively correlated (0.620) with the share of social expenditure for old-age pensions, and negatively correlated (-0.714) with the share of older adults living in institutions. This is in accordance with Reher's "strong family" hypothesis, and with the idea that these deeply-rooted differences may have shaped the institutional settings. However, a causal feedback cannot be ruled out as well. What is important here is that "latest-late" transitions out of the parental home are more common in countries in which the welfare is strongly directed towards the elderly, and in which, according to the literature, the elderly have a stronger say in family ties (see i.e. Glaser and Tomassini, 2000 and 
Tomassini et al., 2003). The same consistent picture arises when we look at indicators of the socio-economic status of young adults. The median age at leaving home is negatively correlated with the relative risk of becoming poor during early adulthood ($0.522)$, and with the suicide rate (-0.430): note that the correlation between suicide rates and poverty is lower in absolute terms being 0.280 . There seem to be some advantages of the "strong family" model with late independence in terms of protection of young adults from poverty and mental breakdown (Note 10). Of course, we cannot translate directly these correlations to the individual level: we may, however, speculate that in countries characterized by the "strong family", when the family is weak (given the lack of welfare), poverty and other problems may become much more important (again, this is the interaction of institutional setting and individual-level features). The strength of the family goes also against the strength of welfare transfers and of other types of relationships: the median age at leaving home is negatively correlated with unemployment benefits (in terms of replacement rate) for singles (-0.387), and with the participation in associations or other non-profit organizations (-0.562).

Table 6: $\quad$ Cross-country correlation matrix between indicators of home-leaving timing and other indicators in European FFS countries (end of the 1990s).

\begin{tabular}{llllllll}
\hline & LHOME & POVER & PENSIO & INSTIT & SUICIDE & REPLAC & ASSOC \\
\hline LHOME & 1.000 & & & & & & \\
POVER & -0.522 & 1.000 & & & & & \\
PENSIO & 0.620 & -0.628 & 1.000 & & & & \\
INSTIT & -0.714 & 0.771 & -0.718 & 1.000 & & & \\
SUICIDE & -0.430 & 0.280 & -0.398 & 0.211 & 1.000 & & \\
REPLAC & -0.387 & 0.664 & -0.450 & 0.499 & 0.157 & 1.000 & \\
ASSOC & -0.562 & 0.667 & -0.730 & 0.854 & 0.256 & 0.196 & 1.000 \\
\hline
\end{tabular}

Note: data refer to 19 countries (with some missing values). Raw data are available from the author upon request.

Definition and sources: LHOME: Billari et al. (2001), UN/ECE FFS Standard Country Tables:

http://www.unece.org/ead/pau/ffs/ffs_standtabframe.htm. Data refer to women of cohorts born around 1960;

POVER: Relative risk of poverty: share of population in age 18-25 in poverty (below $50 \%$ of median adjusted disposable income of the entire population) divided by share of population in age 18-25. Source: Förster (2000); PENSIO: Expenditure in pension divided by total social expenditure, 1997. Source: OECD (2000); INSTIT: Share of population aged 65 and over in institutions (mid-1990s). OECD online database; SUICIDE: Suicide rates. OECD (from World Health Organisation, 2001, Mental health project on suicide prevention named "Live your life"). Data on ages 25-34; REPLAC: Wage replacement rate for unemployed singles. Source OECD online database, Benefits and Wages, OECD Indicators; ASSOC: Average number of associations and groups individuals belong to (ages 25-50). OECD (Inglehart et al., 2000), World Values Surveys and European Values Surveys, 1981-1984, 1990-1993, and 1995-1997 [Computer file]. ICPSR version. Ann Arbor, MI: Institute for Social Research [producer], 2000. Ann Arbor, MI: Inter-university Consortium for Political and Social Research [distributor], 2000. 
All these analyses suffer from the weakness of the technique, but they do not falsify the idea that transitions to adulthood, and in particular the departure from the parental home, may be rooted in systems that are consistent and particularly resisting to changes and common trends. If we look at the motivation behind what youth thinks about late home-leaving (Table 7), it is precisely in Sweden (with a high state support) that we see the highest share of "can't afford to move out" answer, although Spain shows an equally high level in 2001. Housing problems are named more frequently in the Netherlands (where the state supports housing to a great extent). "New modern" strong ties (parents are less strict) are more frequently cited in Greece and Italy, Austria and Germany, indicating the feeling that co-residence is more often a choice there, with respect to other countries. We can thus conclude this part by hypothesizing that the two opposite patterns "latest-late" and "earliest-early" are consistent with the macro-level situation of the respective societies (familialistic welfare state on the one hand, and

Table 7: $\quad$ Share of young adults (age 15-24) who mention reasons for why youth are living longer at their parents' home. European Union (15 states).

\begin{tabular}{lllllll}
\hline & \multicolumn{2}{l}{ Can't afford to move out } & \multicolumn{2}{l}{ Not enough suitable housing } & \multicolumn{2}{l}{ Parents are less strict } \\
& 1997 & 2001 & 1997 & 2001 & 1997 & 2001 \\
\hline Austria & 58 & 57 & 45 & 26 & 27 & 35 \\
Belgium & 61 & 54 & 19 & 9 & 32 & 24 \\
Denmark & 64 & 63 & 44 & 56 & 30 & 31 \\
Finland & 79 & 75 & 34 & 44 & 32 & 27 \\
France & 86 & 75 & 19 & 20 & 31 & 26 \\
Germany & 62 & 58 & 29 & 17 & 35 & 39 \\
Germany (East) & 69 & 64 & 41 & 13 & 33 & 31 \\
Germany (West) & 61 & 56 & 31 & 19 & 36 & 42 \\
Greece & 68 & 72 & 8 & 7 & 26 & 36 \\
Ireland & 71 & 74 & 25 & 40 & 24 & 22 \\
Italy & 72 & 60 & 17 & 14 & 34 & 34 \\
Luxembourg & 52 & 50 & 22 & 22 & 33 & 19 \\
Netherlands & 72 & 49 & 37 & 52 & 26 & 31 \\
Portugal & 65 & 52 & 42 & 30 & 26 & 21 \\
Spain & 80 & 82 & 32 & 35 & 15 & 18 \\
Sweden & 95 & 81 & 34 & 49 & 14 & 20 \\
United Kingdom & 78 & 77 & 39 & 32 & 21 & 17 \\
EU 15 & 74 & 67 & 28 & 25 & 28 & 28 \\
& & & & & & \\
Coefficient of variation & 10.96 & 11.35 & 10.69 & 15.10 & 6.24 & 6.99 \\
between countries & & & & & &
\end{tabular}

Source: Eurobarometer (INRA, 2001). The coefficient of variation is computed using the data for Germany only (not distinguishing East and West Germany). 
social-democratic welfare state on the other hand) and are thus fairly stable equilibria. Maybe the in-between situations (early home-leaving in liberal market countries, and medium home-leaving in conservative welfare countries) are not as stable as the extreme case. As intergenerational relationships substantially shape these two extreme patterns "latest-late" and "earliest-early", the future aging population, with a quicker aging in "latest-late" countries (Billari et al., 2000), may be the challenge that will put the very existence of such patterns in discussion.

\section{Discussion}

We have illustrated the idea that extreme cases (and their opposites) in demographic research are important challenges for researchers. We have also noticed that the heterogeneity of European countries is a blessing for scholars interested in studying the importance of macro-level conditions in shaping the life courses of youth. The transition to adulthood in Europe, with the "latest-late" pattern of Southern Europe, provides an extreme case among industrialized countries. This extreme case can be compared to its opposite that we dare call the "earliest-early" pattern of transition to adulthood in Nordic countries. Explaining the emergence and persistence of such extreme cases implies references to multifaceted approaches. Welfare state and institutional arrangements, historical and deeply rooted cultural differences, as well as economic and policy factors, and ideational change, all contribute in creating an extreme case at the national level. Such factors also contribute in explaining that microlevel life course determinants play different roles in different European societies. Given current knowledge, and the ideas that first there may be multiple equilibria in the way the transition to adulthood is shaped (if there are equilibria at all), and second path dependence assures that the present and past situation affects the future course, extreme cases can be quite stable and population aging may become the main homeostatic force contributing to a convergence of behavior.

Future research on becoming an adult in Europe will gain a great advantage from the new generation of longitudinal surveys, coupled with contextual-level databases that is foreseen for instance in the Generations and Gender Programme since its inception (Hoem et al., 2000). These surveys, with their multidisciplinary orientations, will allow researchers to assess the relative weight of factors in shaping international differences. We agree with Lesthaeghe (1998) that demographers should avoid "disciplinary soccer games" like in the culture vs. economy debate, but we also see the need for assessing the relative importance of different types of factors. Our provocative ideas on crosscountry correlations between age at home-leaving and other socio-economic indicators, and on the "two patterns" of transition to adulthood, also call for a greater importance 
of the study of implications of demographic events, both at the individual and at the social level. A greater attention placed on the implications of demographic events will be of enormous importance to understand the meaning of such events in a heterogeneous Europe.

\section{Acknowledgements}

The author would like to thank two anonymous referees of Demographic Research for their useful comments and suggestions. 
Demographic Research - Special Collection 3: Article 2

-- Contemporary Research on European Fertility: Perspectives and Developments --

\section{Notes}

1. In the paper we will often make use of research that has been carried on within the Research Group on the Demography of Early Adulthood at the Max Planck Institute for Demographic Research in the period 1999-2002.

2. Of course, societal transformations sharply affecting institutional settings have taken place in Europe, and not only in Central and Eastern Europe after the fall of the Iron Curtain. Three countries in Southern Europe (Greece, Spain, and Portugal) found their way out of dictatorship only in the mid 1970s.

3. Esping-Andersen $(1999,94)$ states: "a simple 'three worlds' typology may suffice for most of the purposes that this book pursues. The final judgment is not yet in, and we shall in fact see that the distinctiveness of the Southern European countries does make its mark on issues such as post-industrial employment adaptation."

4. "Familialistic" according to Esping-Andersen (1999).

5. This four-type categorisation is consistent with Ferrera (1996), Trifiletti (1999) and Mayer (2001). The typologies outlined have been criticised by feminists for their lack of genderization, and other groupings of countries have been proposed (see the review of Neyer, 2003).

6. See also Monnier and Rychtarikova (1991).

7. For a critical view on the individualization thesis as applied to the transition to adulthood see Schizzerotto and Lucchini (2002).

8. Some scholars put together the four types of explanations we have discussed to develop clusters of countries. Mellens (1999a; 1999b) develops a clustering of European countries based on demographic and socio-economic variables. This clustering is used to define the "diversity" of European countries that lies under scenarios for population projections (de Beer and van Wissen, 1999). Five clusters are identified, according to the dominant "culture": 1) the maternalistic cluster including the five Nordic countries (Denmark, Finland, Iceland, Norway, and Sweden), which as a main characterization has "the relatively high level of female participation in the labor market, the high level of childcare facilities and the fact that female values like co-operation are emphasized", together a "relatively low level of individualism and conservativism" (Mellens, 1999b, 34); 2) the pragmatic cluster includes Austria, Belgium, France, Germany, Ireland, Luxembourg, Netherlands, Switzerland, and the United Kingdom, with high emphasis on economic performance and "not extreme" scores on the equality of gender roles and conservativism; 3) the paternalistic cluster including Southern European 
countries (Greece, Italy, Portugal, and Spain), with "the prevalence of traditional family values, the lack of female emancipation and the low level of childcare facilities" (Mellens, 1999b, 36), with high scores on conservativism and low on gender equality; 4) the intermediate culture, in Central Europe (Croatia, Czech Republic, Estonia, Hungary, Latvia, Lithuania, Poland, Slovak Republic, and Slovenia), which characterizes the more westernized of the former communist countries; 5) the post-totalitarian cluster (Belarus, Bulgaria, Moldova, Romania, Russia, and Ukraine), with an "incomplete transition to a capitalist structure" (Mellens, 1999b, 37). In building population scenarios, it is assumed that the differences among clusters persist, although convergence within clusters will be observed. A similar approach is adopted by Pinnelli et al. (2001).

9. The median age is refereed to women of cohorts born around 1960. As crossnational differences are rather persistent (Corijn and Klijzing, 2001; Billari and Wilson, 2001), this figure can be considered as representative of the home-leaving pattern at the national level.

10. Research on home-leaving in the United Kingdom has traditionally been concerned with the poverty risks of youth leaving home at early ages (Jones, 1995). 
Demographic Research - Special Collection 3: Article 2

-- Contemporary Research on European Fertility: Perspectives and Developments --

\section{References}

Aassve, A., Billari, F.C., Mazzuco, S., and Ongaro, F., 2002. "Leaving home: A comparative analysis of ECHP data." Journal of European Social Policy 12 (4): 259-276.

Aassve, A., Billari, F.C., and Spéder, Z., 2003. "Family formation during the Hungarian societal transition: trends in postponement and the impact of policy changes." Unpublished manuscript.

Ahn, N., and Mira, P., 2002. "A note on the changing relationship between fertility and female employment rates in developed countries." Journal of Population Economics 15 (4): 667-682.

Andersson, G., 2000. "The impact of labor-force participation on childbearing behavior: Pro-cyclical fertility in Sweden during the 1980s and the 1990s." European Journal of Population 16: 293-333.

Baizán, P., Aassve, A., and Billari, F.C., 2002. "Institutional arrangements and life course outcomes: The interrelations between cohabitation, marriage and first birth in Germany and Sweden.” MPIDR WP 2002-026. Max Planck Institute for Demographic Research, Rostock.

Barbagli, M., Castiglioni, M., and Dalla Zuanna, G., 2003. Fare famiglia in Italia. Un secolo di cambiamenti. Il Mulino, Bologna.

Beck, U., 1992. Risk Society: Towards a New Modernity. Sage, London.

Bernardi, F., 2000. "Globalization, recommodification and social inequality: Changing patterns of early careers in Italy." Globalife Working Paper Series No. 07. Faculty of Sociology at the University of Bielefeld, Bielefeld.

Billari, F.C., 2004. "Will the new demography focus on oldest-old, lowest-low, and latest-late?" Forthcoming on the Proceedings of the Chaire Quetelet 2002, Université Catholique de Louvain, Louvain-la-Neuve.

Billari, F.C., Castiglioni, M., Castro Martìn, T., Michielin, F., and Ongaro, F., 2002. "Household and union formation in a mediterranean fashion: Italy and Spain." In: Klijzing, E., and Corijn, M. (eds), Fertility and Partnership in Europe: Findings and Lessons from Comparative Research. Volume II. United Nations, Geneva/New York: 17-41.

Billari, F.C., and Kohler, H.-P., 2004. "Patterns of lowest-low fertility in Europe." Population Studies 58 (2); forthcoming. 
Billari, F.C., Manfredi, P., and Valentini, A., 2000. "Macro-demographic effects of the transition to adulthood: Multistate stable population theory and an application to Italy." Mathematical Population Studies 9 (1): 33-63.

Billari, F.C., Philipov, D., and Baizán, P., 2001. "Leaving home in Europe. The experience of cohorts born around 1960." International Journal of Population Geography 7 (5): 339-356.

Billari, F.C., and Wilson, C., 2001. "Convergence towards diversity? Cohort dynamics in the transition to adulthood in contemporary Western Europe." MPIDR WP 2001-039. Max Planck Institute for Demographic Research, Rostock.

Blossfeld, H.-P., 2000. "Globalization, social inequality and the role of country-specific institutions - open research questions in a learning society." Globalife Working Paper Series No. 11. Faculty of Sociology at the University of Bielefeld, Bielefeld.

Bongaarts, J., and Watkins, S.C., 1996. "Social interactions and contemporary fertility transitions." Population and Development Review 22 (4): 639-682.

Buchmann, M., 1989. The Script of Life in Modern Society. Entry into Adulthood in a Changing World. University of Chicago Press, Chicago.

Coleman, D., 2002. "Populations of the industrial world - a convergent demographic community?" International Journal of Population Geography 8: 319-344

Corijn, M., and Klijzing, E. (eds), 2001. Transitions to Adulthood in Europe. Kluwer Academic Publishers, Dordrecht.

Dalla Zuanna, G., 2001. "The banquet of Aeolus: A familistic interpretation of Italy's lowest low fertility." Demographic Research 4 (5). Available http://www.demographic-research.org/Volumes/Vol4/5.

de Beer, J., and van Wissen, L. (eds), 1999. Europe: One Continent, Different Worlds. Population Scenarios for the $21^{\text {st }}$ Century. Kluwer Academic Publishers, Dordrecht: 33-44.

Engelhardt, H., and Prskawetz, A., 2004. "On the changing correlation between fertility and female employment over space and time." European Journal of Population 20: $35-62$.

Esping-Andersen, G., 1999. Social Foundations of Postindustrial Economies. Oxford University Press, Oxford. 
Fernandez Cordón, J.A.,1997. "Youth residential independence and autonomy: A comparative study." Journal of Family Issues 16: 567-607.

Ferrera, M., 1996. "Il modello Sud-Europeo di welfare state." Rivista Italiana di Scienza Politica 1: 67-101.

Förster, M., 2000. "Trends and driving factors in income distribution and poverty in the OECD area." Labour Market and Social Policy Occasional Paper No. 42. OECD, Paris.

Giddens, A., 1990. The Consequences of Modernity. Polity Press, Cambridge.

Glaser, K., and Tomassini, C., 2000. "Proximity of older women to their children: A comparison of Britain and Italy." The Gerontologist 40: 729-737.

Goldscheider, F., 2000. "Why study young adult living arrangements? A view of the second demographic transition." Paper presented at the workshop Leaving home: A European focus, Max Planck Institute for Demographic Research, September 2000, Rostock.

Hajnal, J., 1965. "European marriage patterns in perspective." In: Glass, D. and Eversley, D. (eds), Population in History: Essays in Historical Demography. Edward Arnold, London: 101-143.

Hobcraft, J., and Kiernan, K., 1995. "Becoming a parent in Europe." Welfare State Program Discussion Paper Series No. 116. Suntory and Toyota International Centres for Economics and Related Disciplines, London.

Hoem, B., 2000. "Entry into motherhood in Sweden: the influence of economic factors on the rise and fall in fertility, 1986-1997." Demographic Research 2 (4). Available http://www.demographic-research.org/Volumes/Vol2/4.

Hoem, B., and Hoem, J.M., 1997. "Sweden's family policies and roller-coaster fertility." Jinko Mondai Kenkyu (Journal of Population Problems) 52: 1-22.

Hoem, J.M., Aassve, A., Andersson, G., Baizán, P., Billari, F.C., Engelhardt, H., Fürnkranz-Prskawetz, A., Hank, K., Huinink, J., Kohler, H.-P., Kohlmann, A., Kreyenfeld, M., Neyer, G., and Vikat, A., 2000. "The ECE/PAU generations and gender programme: Concepts for a second round of fertility and family surveys in Europe, with particular attention paid to persons of reproductive/working age." In: UNECE/UNFPA, Generations and Gender Programme. Exploring Future Research and Data Collection Options. United Nations, Geneva: 59-104.

Holdsworth, C., 2000. "Leaving home in Britain and Spain." European Sociological Review 16: 201-222. 
INRA, 2001. “Les jeunes européennes en 2001.” Eurobarometre 55.1.

Inglehart, R., et al., 2000. World Values Surveys and European Values Surveys, 19811984, 1990-1993, and 1995-1997 [Computer file]. ICPSR version. Ann Arbor, MI: Institute for Social Research [producer] and Inter-University Consortium for Political and Social Research [distributor].

Jones, G., 1995. Leaving home. Open University Press, Buckingham/Philadelphia.

Kiernan, K., 1986. "Leaving home: Living arrangements of young people in six WestEuropean countries." European Journal of Population 2: 177-184.

Kögel, T., 2004. "Did the association between fertility and female employment within OECD countries really change its sign?" Journal of Population Economics 17: 45-65.

Kohler, H.-P., 2000. "Die neue Demografie." MPIDR WP 2000-014. Max Planck Institute for Demographic Research, Rostock.

Kohler, H.-P., 2001. Fertility and Social Interactions: An Economic Perspective. Oxford University Press, Oxford.

Kohler, H.-P., Billari, F.C., and Ortega, J.A., 2002. "The emergence of lowest-low fertility in Europe during the 1990s. "Population and Development Review 28 (4): 641-680.

Laslett, P., 1983. "Family and household as work group and kin group: Areas of traditional Europe compared." In: Wall, R., Robin, J. and Laslett, P. (eds), Family Forms in Historic Europe. Cambridge University Press, Cambridge: 513-563.

Lesthaeghe, R., 1998. "On theory development: Applications to the study of family formation." Population and Development Review 24 (1): 1-14.

Lesthaeghe, R., 2001. "Postponement and recuperation: Recent fertility trends and forecasts in six Western European countries." IPD-WP 2001-1. Interface Demography SOCO, Vrije Universiteit Brussel, Brussels.

Lesthaeghe, R., and van de Kaa, D., 1986. "Twee demografische transities?" In: Lesthaeghe, R., and van de Kaa, D. (eds), Bevolking: Groei en Krimp. Van Loghum Slaterus, Deventer: 9-24.

Liefbroer, A., 1999. "From youth to adulthood: Understanding changing patterns of family formation from a life course perspective." In: van Wissen, L., and 
Dykstra, P. (eds), Population Issues. An Interdisciplinary Focus. Kluwer Academic/Plenum Publishers, New York.

Mayer, K.U., 2001. "The paradox of global social change and national path dependencies: life course patterns in advanced societies." In: Woodward, A.E., and Kohli, M. (eds), Inclusions-Exclusions. Routledge, London: 89-110.

Mayer, K.U., and Müller, W., 1986. "The state and the structure of the life course." In: Sorensen, A., Weinert, F., and Sherrod, L. (eds), Human Development and the Life Course: Multidisciplinary Perspectives. Lawrence Erlbaum Associates Publishers, Hillsdale, NJ: 217-245

Mellens, M., 1999a. "Determinants of demographic behaviour." In: de Beer, J., and van Wissen, L. (eds), Europe: One Continent, Different Worlds. Population Scenarios for the $21^{\text {st }}$ Century. Kluwer Academic Publishers, Dordrecht: 5-32.

Mellens, M., 1999b. "Uniformity and diversity defined." In: de Beer, J. and van Wissen, L. (eds), Europe: One Continent, Different Worlds. Population Scenarios for the $21^{\text {st }}$ Century. Kluwer Academic Publishers, Dordrecht: 33-44.

Micheli, G.A., 2000. "Kinship, family and social network. The anthropological embedment of fertility change in Southern Europe." Demographic Research 3 (13). Available http://www.demographic-research.org/Volumes/Vol3/13/.

Mitterauer, M., 1992. A History of Youth. Blackwell, Oxford.

Modell, J., Furstenberg F., and Hershberg, T., 1976. "Social change and transitions to adulthood in historical perspective." Journal of Family History 38: 7-32.

Monnier, A., and Rychtarikova, J., 1991. "The division of Europe into East and West." Population: An English Selection 4: 129-160.

Montgomery, M.R., and Casterline, J., 1996. "Social learning, social influence and new models of fertility." Population and Development Review 22, Supplement: 151175 .

Neyer, G.R., 2003. "Family policies and low fertility in Western Europe.” MPIDR WP 2003-021. Max Planck Institute for Demographic Research, Rostock.

OECD, 2000. Social Expenditure Database, 1980-1997. OECD, Paris.

Persson, T., and Tabellini, G., 2000. Political Economics. Explaining Economic Policy. MIT Press, Cambridge, MA.

Pfau-Effinger, B., 1999. "Change of family policies in the socio-cultural context of European societies." Comparative Social Research 18: 135-159. 
Pinnelli, A., Hoffman-Nowotny, H.J., and Fux, B., 2001. "Fertility and new types of households and family formation in Europe." Population Studies 32. Council of Europe Publishing, Strasbourg.

Reher, D.S., 1998. "Family ties in Western Europe: persistent contrasts." Population and Development Review 24: 203-234.

Rindfuss, R.R., 1991. "The young adult years: diversity, structural change and fertility." Demography, 28 (4): 493-512.

Schizzerotto, A., and Lucchini, M., 2002. "Transitions to adulthood during the twentieth century. A comparison of Great Britain, Italy and Sweden." EPAG Working Paper 2002-36. University of Essex, Colchester.

Surkyn, J., and Lesthaeghe, R., 2004. "Value orientations and the Second Demographic Transition (SDT) in northern, western and southern Europe: An update." Demographic Research: this Special Collection.

Thornton, A., 2001. "The developmental paradigm, reading history sideways, and family change." Demography 38 (4): 449-465.

Tomassini, C., Wolf, D.A., and Rosina, A., 2003. "Parental housing assistance and parent-child proximity in Italy." Journal of Marriage and the Family 65: 700715 .

Trifiletti, R., 1999. "Southern European welfare regimes and the worsening position of women." Journal of European Social Policy 9: 49-64.

van de Kaa, D., 1987. "Europe's Second Demographic Transition." Population Bulletin 42 (1). Population Reference Bureau, Washington, DC.

van de Kaa, D., 1997. "Options and sequences: Europe's demographic patterns." Journal of the Australian Population Association 14: 1-29.

Vaupel, J., 2000. "Longevity and fertility: How are the industrial countries aging? Are our projections reliable?" In: CSIS Policy Summit on Global Aging. The Graying of the Industrial World. January 2000, Washington, DC.

Wachter, K., 2003. "The past, present and future of demography and the role of the Max Planck Institute for Demographic Research.” Demographic Research 9 (4): 69-80. Available http://www.demographic-research.org/Volumes/Vol9/4.

Wall, R., 1989. "Leaving home and living alone: An historical perspective." Population Studies 43: 369-389. 
Demographic Research - Special Collection 3: Article 2

-- Contemporary Research on European Fertility: Perspectives and Developments --

Wall, R., 1995. "Historical development of the household in Europe." In: van Imhoff, E., Kujisten, A., and van Wissen, L. (eds), Household Demography and Household Modeling. Plenum Press, London: 19-52. 
Demographic Research - Special Collection 3: Article 2 -- Contemporary Research on European Fertility: Perspectives and Developments -- 